\title{
Constructing Interior Design Pedagogy
}

\author{
MICHAEL HUGHES
}

American University of Sharjah

This paper explores the nascent state of hands-on pedagogy within interior design education with regard to the impact of design-build precedents native to architectural curricula, as well as the challenges imposed by conventional assumptions linked to intellectual hierarchies and gender bias. Two primary models are emerging: Objects and the, less common, Augmentation. These methods will be discussed and illustrated with examples drawn from schools in North America and the Middle East. Taken together the methods and projects structure an evolving taxonomy for pedagogies of making in interior design.

\section{OPTIC AND GENDER BIAS}

Design pedagogies associated with material exploration, making and full-scale empirical study struggle to overcome entrenched academic bias that privilege the optic over the haptic and the intellectual over the physical. In The Architecture of the Seven Senses Juhani Pallasmaa notes that, "In Renaissance times, the five senses were understood to form a hierarchical system from the highest sense of vision down to the lowest sense, touch." ${ }^{1}$ Even earlier, Greek philosophers ranked the senses and elevated vision to the top where it is associated with, but inferior to ideas and intellect. ${ }^{2}$

The ubiquity of the sight-intellect paradigm founded in Idealism informs the transformation of guild-based building trades into the development of the codified design professions. For example, a review of the literature on the historical development, or invention, of the professional Architect describes a distancing from the site-based tactile knowledge of craftsmen toward the sight-centric focus on design as an activity physically and intellectually segregated from tactile experience with materials or construction. In her book From Craft to Profession: The Practice of Architecture in Nineteenth-Century America, Mary Woods highlights a passage from Benjamin Henry Latrobe in which he foregrounds the bifurcation of theory and practice-

The profession of Architecture has been hitherto in the hands of two sets of Men. The first of those [gentlemen] who from travelling or from books have acquired some knowledge of the theory of Art, know nothing of its practice, the second of those [mechanics] who know nothing but the practice... ${ }^{3}$

Similarly, and largely in parallel with the advent of US architectural licensure in 1857, the academic studio emerges as the source of disciplinary knowledge where schools increasingly "highlight the importance of pure design by removing from its study key aspects of professional practice" such as communal effort, construction and collaboration." ${ }^{4}$

For Interior Design the path to, and definition of, professionalization has been further removed from the physical by the fact that, "Interior design has historically occupied a marginal place within the cultural hierarchy, as a feminized sphere of activity." ${ }^{5}$ Latrobe's reference to the "Men" of Architecture speaks to the history of gender-based bias stigmatizing women's direct engagement with building production and non-domestic physical labor. Even in the realm of DIY (do it yourself) home improvement Jen Browne finds that in postwar British advertising "women were rarely shown actually DIYing." ${ }^{6}$ As such, "the acts of shopping for materials, designing interior schemes and executing the DIY ae nevertheless presented as consumption, not production." ${ }^{7}$ Despite subsequent progress in feminist studies, gender equity laws and women's empowerment broadly as well as professional identity in the discipline perceptions of Interior Design relative to gender specificity persist. Writing in 1999 William W. Braham found that gender-based segregation still dominates Interior Design:

Although interior design constitutes one of the many divisions of labor within the modern building trades, the distinction is a highly gendered one, in which the activities and individual engaged in it are implicitly assumed to be feminine. The gender connotation derives partly from the fact that women dominate the profession of interior design, a situation conditioned by the removal of men and their work from the home in the nineteenth and twentieth centuries. ${ }^{8}$

\section{HAPTIC PEDAGOGIES}

In the 20th century an alternative, Progressive pedagogy of "learning through experience" experiential learning and "intelligent action" emerged in education theory as a counterpoint to the prevalent, 'traditional' approach based on the "essentially static... acquisition of what already is incorporated in books" through the "narrative character" of mechanical memorization. ${ }^{9,10,11}$ The theory of experience championed by Dewey parallels curricular developments at the Bauhaus that later informed the methodologies of making practiced at Black Mountain College and the Cranbrook Academy of Art. In architecture these precedents influenced 


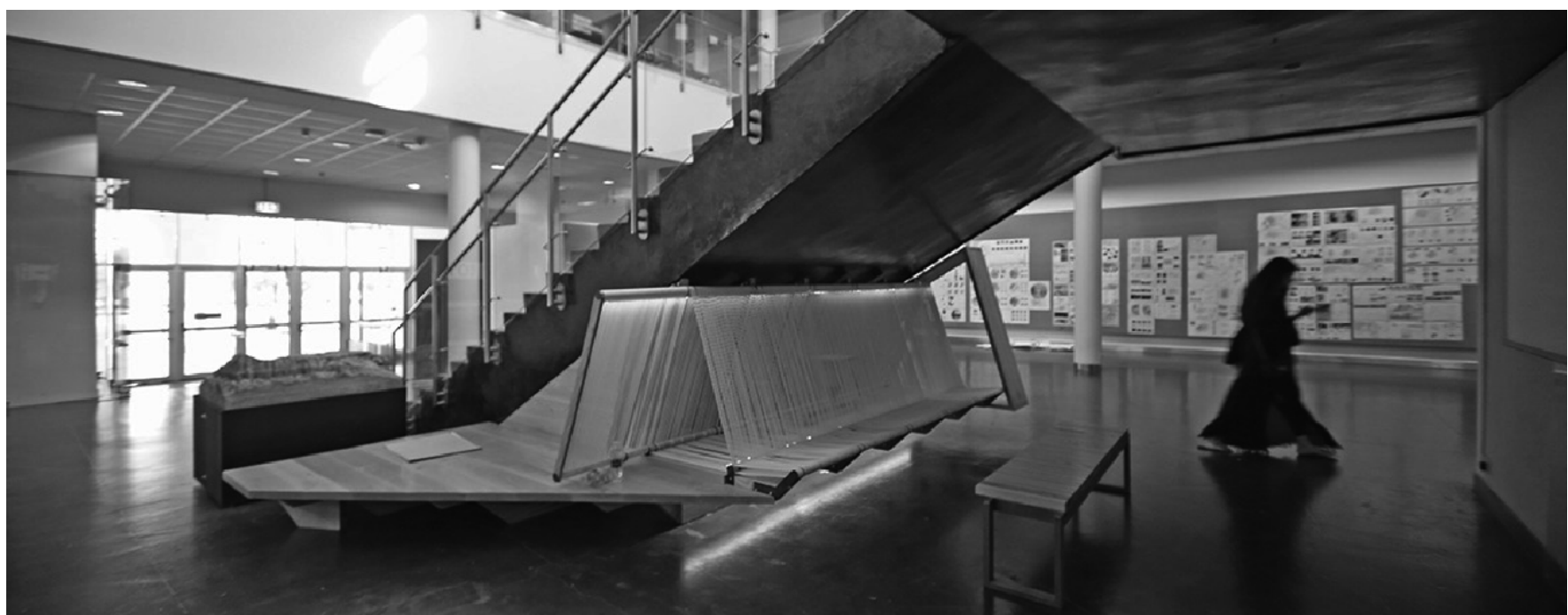

Figure 1: Theatre Under the Stairs, IDE 402 Interior Design-Build Studio at the American University of Sharjah, Spring 2017. Professor: Daniel Chavez.

the development of academic 'design-build' coursework. This full-scale teaching/learning format, "extends beyond the traditional notions of design to span into the realm of making" and broadens "the definition of the discipline of architecture." ${ }^{12}$ Or as Bryan Mackay-Lyons has argued, design-build returns the discipline to, "its roots in the master-builder tradition of the Middle Ages." ${ }^{13}$ In either case, the current design-build paradigm, derived from the Building Studio developed at Yale University in 1967, typically features consists of 8 to 18 advanced students, along with a faculty member, working directly, at full-scale, on all aspects related to the design and construction of a small building project over the course of a single, academic semester or year. ${ }^{14}$

Beyond Yale interest in this new pedagogy was marginal during the 1970's and 1980's, but by the mid-1990's a small cohort of empirically minded faculty around the US began to experiment with design-build as a viable alternative to conventional drawing-based studios. Led by Samuel Mockbee at Auburn's Rural Studio and Dan Rockhil at the University of Kansas hands-on learning steadily increased in popularity throughout the early 21st century. By 2004 approximately forty schools offered some form of design-build coursework and by 2012100 of the 123-accredited architecture programs had a design-build component ${ }^{15,16}$

Although one-to-one design-build projects in architecture tend to be modest in scope, often focused on small houses, pavilions or bus shelters, they are complex in terms of engaging a wide range of technical, tectonic and logistical challenges. Student participants confront material interaction across multiple systems (foundations, cladding, mechanical, plumbing and electrical), weather proofing, and structural integrity along with client relations, budgets, specifications and code compliance.
The Council for Interior Design Accreditation (CIDA) recognizes 177 undergraduate and graduate Interior Design programs in the United States and 13 in Canada. None of these programs currently offer hands-on experiences commensurate with those commonly found in architecture design-build programs. Literature on the subject is scarce and unlike in architecture there are no books and very few journal articles focused on full-scale work in interior design programs.

In a 2014 paper published in the Journal of Interior Design Margaret Konkel deploys the term "build-to-learn" to describe, "a pedagogical practice reflecting traditions in architectural and engineering education, as well as theoretical foundations in experiential learning" and suggests that her, "analysis reveals a range of build-to-learn experiences being employed in interior design classrooms." ${ }^{17}$ While references include a number of JAE articles authored by architects writing about architectural design-build a closer examination reveals no clear boundary or definition of "build-to-learn." The examples mentioned include a preponderance of merely representational, scale and "conceptual" model-making. The corresponding lack of project specifics, such as project images, names of the faculty or the schools involved, suggests that in 2014 'making' in Interior Design was in a nascent state most frequently exemplified by simple hand-eye coordination exercises, but aspiring to more.

\section{CONSTRUCTING INTERIORS}

Beyond the limited formal, disciplinary literature in there is a growing body of project-based evidence suggesting that a few schools are beginning to engage the potential of hands-on pedagogy in Interior Design. Evidence gleaned from program websites and, in some cases, direct communication with program faculty suggests that a more substantial and diverse range of coursework explicitly devoted to full-scale making is being implemented at a 


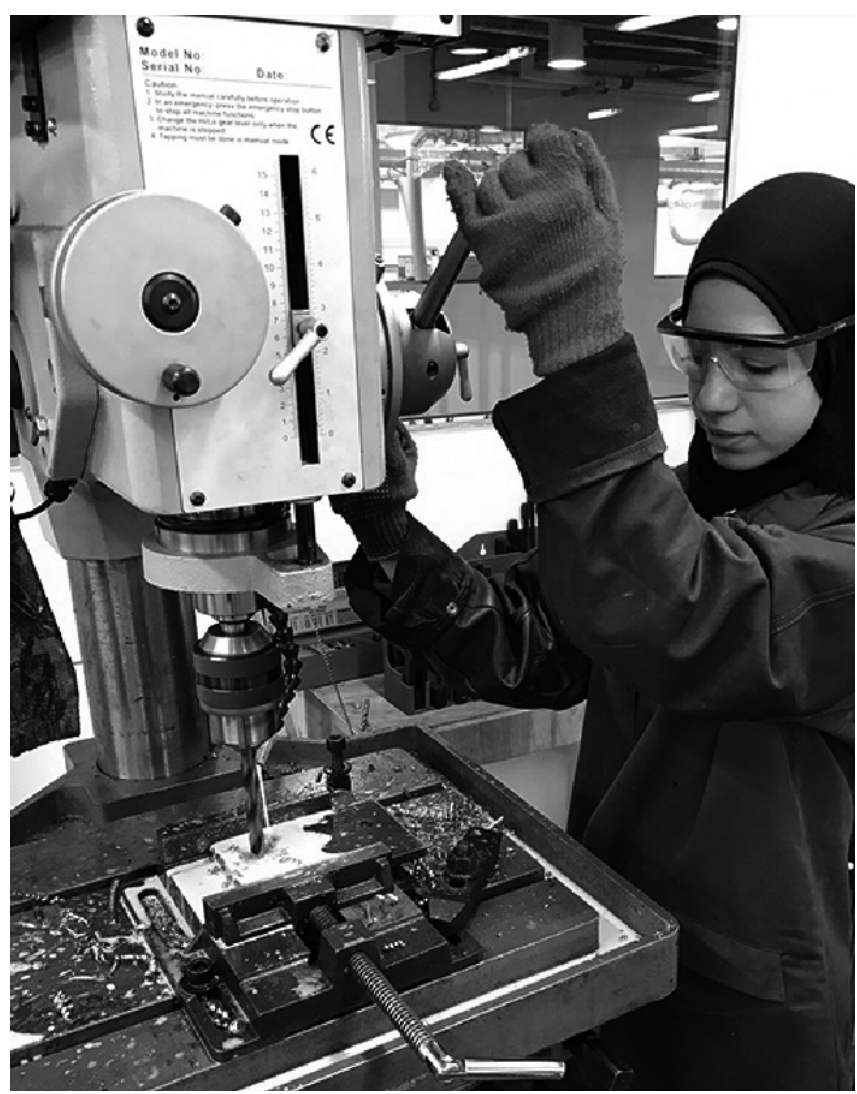

Figure 2: Student working on a full-scale project in the metal lab at the American University of Sharjah.

number of interiors programs, both interior design and interior architecture.

To work at the interior scale is to work at full-scale. In doing so, we find materials are at their true weight, details comply with gravity, and the scale of the body is always present. ${ }^{18}$

The cursory, often aspirational nature of in-house marketing materials such as the "About" section or "Chair's Message" available program statements on showcased on school websites reveals some insight in terms of intent and direction. For example, on the Rhode Island School of Design (RISD) website, Interior Architecture Department Head Liliane Wong suggests a strong link to construction, or reconstruction stating-

Students in our department are engaged in a rich and expansive discipline focusing on the reuse and transformation of existing structures. Through a wide breadth of design in the built environment this exploration includes interior interventions, architectural addition and refurbishment, installation, exhibit design, urban transformations and community engagement - using adaptive reuse as the primary tool. ${ }^{19}$
Elsewhere on the website the second sentence in the description of the 4-year program states, "professors offer hands-on opportunities to learn about practices in the construction industry" and the MDes: Adaptive Reuse is described as, "focused on altering existing structures through interior interventions and adaptive reuse." ${ }^{20,21}$ Taken together the particular choice of terminology in these statements, (ie intervention, addition and altering), suggest a program focused on physical, material and tectonic engagement beyond the decorated surface.

On-line images of student work are few in number, but the available images have been carefully curated to support the program text. Of the six images three are full-scale projects. These include output from a digital fabrication course, a furniture piece and a completed, free-standing installation structure displayed in an existing building. In addition, the inclusion of a physical model built with relatively large pieces of wood suggests engagement with wood-working equipment while a 3-d printed model references digital fabrication facilities. Student names and degree cohort accompany the images, but there is no information linking the work to specific courses or to the broader curriculum structure. A wood shop is located in the building and students have access to a digital fabrication lab shared with the architecture program.

Similarly, the provided curriculum outline only provides course names without insight to any required hands-on component or explanation of the roll of making in the overall course sequence. As a result, it is difficult to determine the nature and frequency of full-scale learning. A close examination of the course descriptions located elsewhere on the website reveals a number of classes concentrated on materials, structural tectonics, digital fabrication and detailing. Full-scale projects are explicitly required in Building Materials Exploration where the course description states-

This class introduces the student to different building materials, their properties and characteristics. Through a series of full scale construction projects and material making processes, the student will be asked to explore these materials and their potential in the design of interior structures. ${ }^{22}$

The focus on direct material engagement and making is even more explicit, and foregrounded, on the Ryerson School of Interior Design website. The program's Promo Video featured at the top of the splash page begins with an image of hand tools hanging in the school's wood shop. Early in the video Assistant Professor Jonathon Anderson states, "Students are introduced to the digital fabrication lab and wood shop very early in their career at RSID in order to advance traditional forms of making." ${ }^{23}$ Throughout the two-plus minute runtime the sequence includes images wood working tools, students actively making in the wood shop and faculty evaluating 
projects created in the wood shop alongside, and integrated with, more traditional drawing-based design studio activity, reviews and alumni interviews.

Following the video the first description of the program in the 'Who We Are' section explains that, "Our teaching is grounded in a commitment to experiential and hands-on learning" followed by an "Our Mission" statement that reads, "To provide a learning environment that balances the theoretical and the practical, the experiential and the conceptual world of design." ${ }^{24}$ The subsequent "Our Pedagogy" statement highlights how the, "experiential curriculum emphasizes both studio and workshop to stimulate creativity, experimentation, problem solving and innovation." 25

As with the RISD on-line images of student work provide limited insight to the link between coursework and making in the curriculum. A photo of a constructed bookcase completed in a 2 nd-year course is accompanied by text stating, "The theory and concepts of human factors engineering (anthropometry, ergonomics) and environmental behavior (proxemics) are explored through the design and construction of full-scale projects." ${ }^{26}$ Additional images of furniture, material studies and digital fabrication projects completed in the 3rd and 4th year coursework speak to the three different hands-on labs support the making agenda at Ryerson. The Design Center serves as a materials library, the Workshop includes traditional and digital fabrication tools, and the Fab Lab, "is a brand new state-of-the-art digital fabrication facility... that supports 3D printing, laser cutting, and CNC milling." 27

\section{METHODS OF MAKING: OBJECTS + AUGMENTATIONS}

The self-described commitment to making evident at RISD and Ryerson, among the top-ranked interiors programs in North America, stands in stark contrast to the conventional assumptions that link interior design to decoration and the application of non-structural surface treatments. ${ }^{28}$ While these two programs are among the most articulate in their support for making a broad review of projects completed at a variety of schools reveals that the interest in making is not isolated.

In the projects surveyed two general categories, or types, Objects and Augmentations, can be distinguished primarily by the degree of engagement with a given site. Set upon floors or shelves Objects allow for discrete, movable operations in, but largely independent of, the physical context. In contrast, Augmentations embed into or onto the site and rely on the existing structure and systems, (electrical, plumbing, HVAC). As such they require a much higher degree of coordination, (both academic and professional), detailing and code compliance.

\section{OBJECTS: FRAGMENTS + FLOATERS}

At this stage, early in the development of full-scale ID pedagogy, Objects dominate, as they are manageable for individual students or small teams operating within the resources commonly available in most school wood and metal shops. They also address the materials, tools and tectonic aspects of making isolated from the external and interpersonal issues confronted in larger, more complex projects. Within the Objects category two sub-types can be identified as Fragments and Floaters.

Fragments are typically associated with required courses in the construction technology sequence, such as the introduction to materials and methods of construction. Fragment projects augment lecture content by allowing students to test some aspect of the coursework at full-scale. Details of millwork or wall sections built of actual materials at full-scale exemplify this project type. In the design studio small projects ranging from building components to cladding studies are woven into a larger studio agenda. This variety of delivery formats allows for significant diversity in terms of learning objectives, project duration, and logistical complexity.

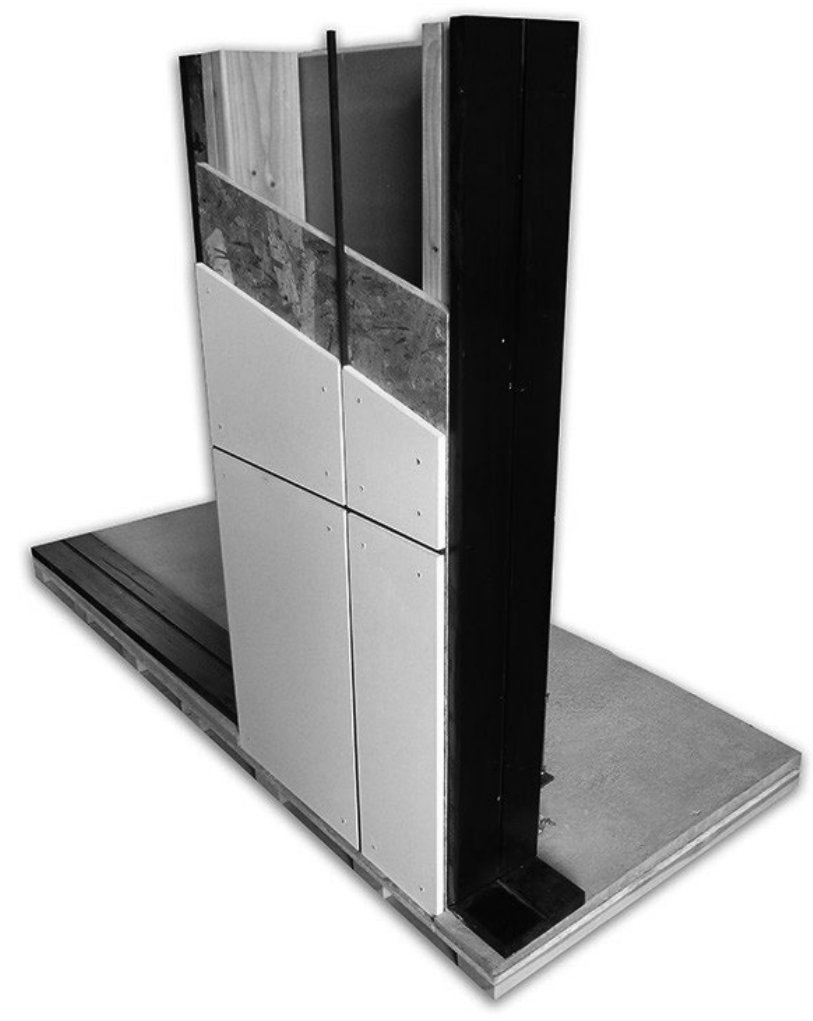

Figure 3: Wall Detail, IDES 433 Construction Documents at University of Nebraska-Lincoln. Professor: Nate Bicak, Student Team: Dani DeGarmo and Samantha Braaten

At the University of Nebraska-Lincoln (UNL) the Interior design program established four themes, including fabricate, intended to run through all courses across the curriculum. Assistant Professor Nate Bicak explains that UNL is, "using making, testing and fabrication as part of the backbone of 
interior design education" ${ }^{29}$ Nebraska embeds fabrication into the curriculum through exercises woven into existing, required coursework. Prof. Bicak introduced the "One to One" program when he, "perceived a disconnect between what they (students) were designing and what it would take to make the thing." ${ }^{30}$ The focus is on typical conditions, such as wall framing and finishes, that are nonetheless new to the students. In one example for their final project students in Prof. Bicak's required construction documents course students build full-scale details of walls designed in their studio project.

The Interior Architecture curriculum at Woodbury University includes two required courses, Tectonics 1 and Tectonics 2, which explore materiality and fabrication. In the first course students develop, "intuitive knowledge of material properties and processes gained through full-scale, hands-on exploration." ${ }^{31}$ Built projects are relatively small and directly reference the body in scale. The second course emphasizes detailing and technical documentation as a fundamental part of the design process.

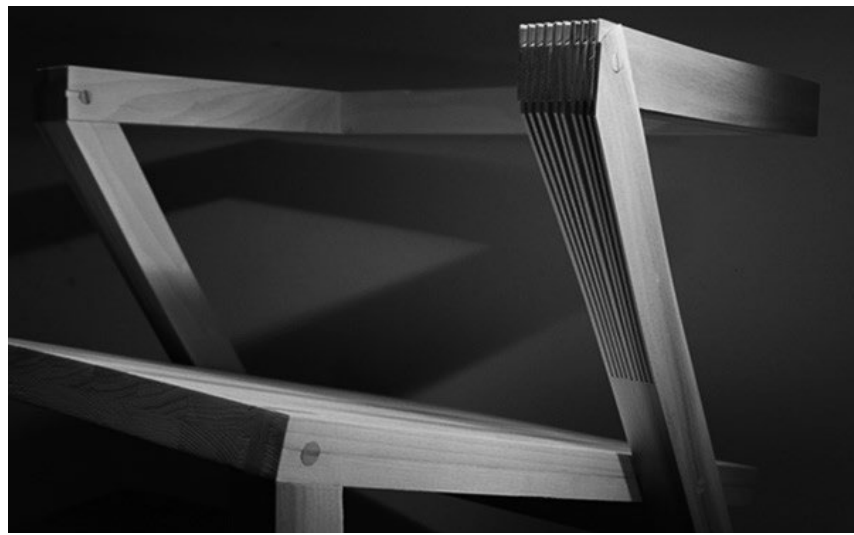

Figure 4: IARC 320A Interior Architecture Studio VI, Marywood University. Professor: Stephen Garrison, Student: Sarah Beernink

Floaters range from small-scale furnishings such as light fixtures and larger, temporary installations that avoid any direct, physical engagement with the existing context. Furniture is the most common project type in this category and it is often the first test when schools begin introducing full-scale coursework. Prof. Jim Sullivan, former Department Chair of Interior Design at Louisiana State University and now Dean at Marywood University identifies two reasons for popularity of furniture making-

First, ID does not have disciplinary culture (drawings, processes) of analyzing contexts, say existing buildings, in the way that architecture does for urban sites or rural landscapes. So when ID does its work, it doesn't know how to affiliate itself in a meaningful way to its locations. Sure, ID accommodates the location where it will be located, but it doesn't understand or utilize site in any generative way. As a result, freestanding work, like furniture, becomes the default.

Second, ID emphasizes the scenographic and visual rather than the tectonic, so when they don't traditionally build or make things directly. When they do engage making, they tend to deploy the materials in a pre-determined form rather than explore properties and inclinations. ${ }^{32}$

Refined furniture pieces produced by students at Kansas State, Ryerson, Marywood, and RISD and featured on their respective websites exemplify the ubiquity of furniture as the common denominator for full-scale work in Interior Design.

Located in a region where manual production is typically discouraged the program at the American University of Sharjah in the United Arab Emirates developed a required furniture design course to introduce full-scale learning opportunities. Initially a single furniture design course was deployed to test student and faculty capacity. The experiment started small both in terms of the scale of the projects and the capacity

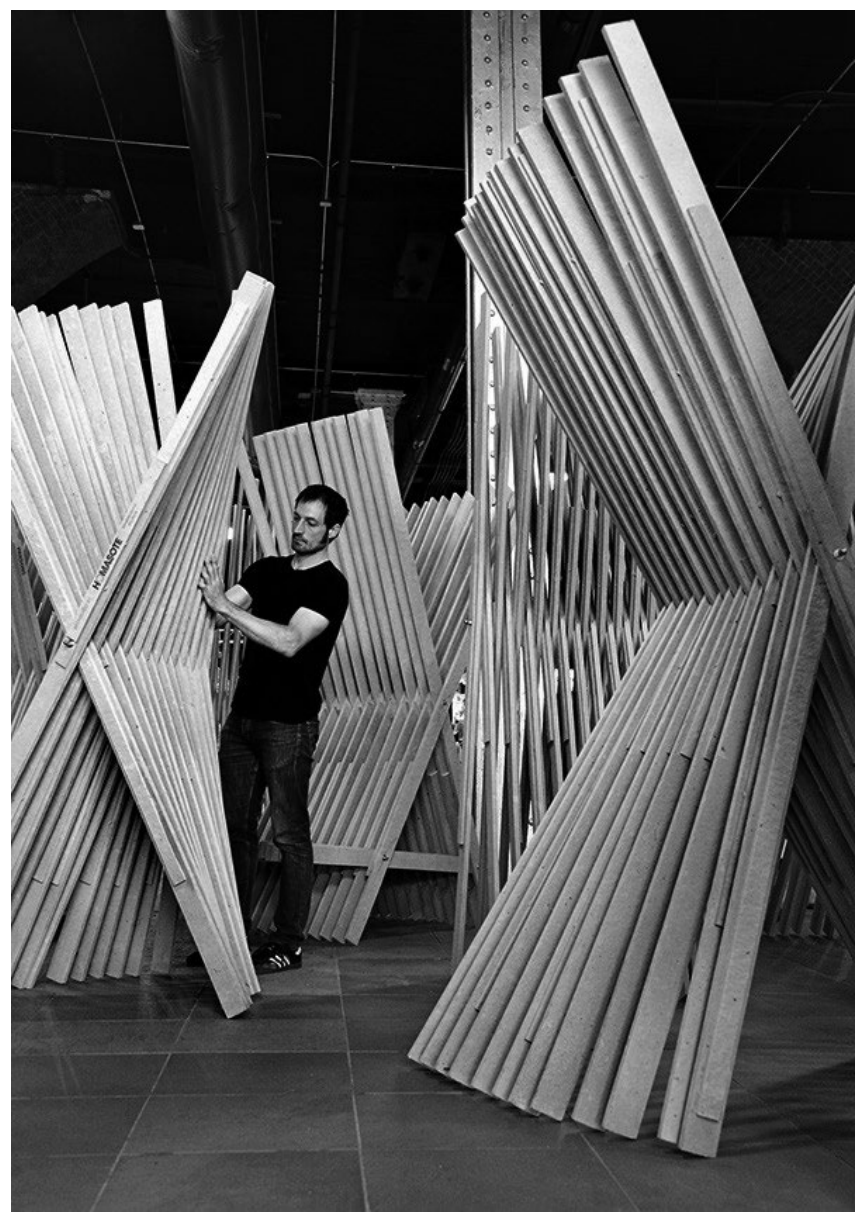

Figure 5: PSCE 3010 Ephemeral Constructions: Temporary Environments at Parsons The New School. Professor: Jonsara Ruth 
of the modest fabrication lab. Despite the hurdles posed by culture and facilities student response was positive and within four years the quality of the outcomes, in terms of craft and design, led to an exhibition invitation at the Milan Furniture Fair and publication in Wallpaper magazine.

Installations play an important role in Graduate MFA program at Parsons The New School. In the first semester Prof. Allan Wexler works with students to create full-scale interventions in presumably ordinary rooms. Inspired by Wexler's own experimental practice the resulting projects introduce material fabrication through site-specific projects that between art and architecture. In the second semester these MFA students enrolled in the Temporary Interiors Workshop create a reception space responding to the theme of the program's annual AFTERTASTE symposium. Given their larger scale temporary and relatively quick production schedule the installations introduce students to occupiable, spatial environments while avoiding the complications associated with permanent constructs. Located early in the course sequence these first-year exercises appear to legitimize full-scale work as a viable tool in the minds of the students which translates and informs much of the MFA thesis work at the school.

\section{AUGMENTATIONS}

In contrast to the proliferation of hands-on coursework at the scale of furniture and installations it is difficult to find evidence of projects that embed themselves structurally and tectonically in the spatial or mechanical systems of existing sites (buildings) as permanent augmentations. The lack of examples is understandable given the extraordinary commitment from participating faculty, administrators and students required to implement larger, more complex projects within the confines defined by academic budgets, teaching loads, curricular structures and semester-based calendars. These challenges become more daunting when students are not exposed to full scale work incrementally throughout the curriculum.

RISD's commitment to hands-on learning, as evident in the required coursework outlined above, provides students with a strong foundation in making. Building on this foundation graduate Interior Architecture students designed, fabricated and installed a new retail environment for the RISD 2nd Life Store in 2015. 2nd Life collects and resells art supplies and materials to the local community and students had to address the storage and display of the diverse inventory. ${ }^{34}$ The final outcome extends skills evident in furniture making by aggregating a series of free-standing units. As assembled the project serves as a curricular bridge between Objects and Augmentations in that it engages a specific site, program and client to significantly alters the spatial and operational conditions while avoiding significant structural and mechanical alteration.

Building on the success of their furniture design program, referenced above, the American University of Sharjah developed a new curriculum designed to embed full-scale learning across the four-year course sequence and beyond freestanding objects. Unique among the programs evaluated for this paper, the AUS initiative includes a required designbuild studio for all 4th year Interior Design students.

The design-build studio is supported by a suite of courses, from an introductory to an advanced level, developed as a coherent stream existing within the broader program curriculum. The design and construction of a light fixture has been embedded in the required 2 nd year 'Color and Light' lecture course and a range of Introductory and Advanced Material Fabrication (aka Analog), Furniture Design, and Digital Fabrication electives provide incremental steps to proficiency.

Introduced in 2015 the design-build studio projects address underused spaces within the College of Architecture, Art and Design and across the campus. This proximity allows students to revisit the site frequently during the design and fabricaiton process. Four projects have been completed to date and two of these were recognized with design awards from the American Institute of Architects Middle East chapter.

\section{CONCLUSION}

The emerging, full-scale coursework reviewed in this paper are more speculative than evidentiary of a coherent or cohesive curricular movement. The terms Fragments, Floaters and Augmentation are semantic constructs of the author designed to serve as temporary markers in the evolution of hands-on pedagogy specific to Interior Design and Interior Architecture.

In the current stage of development, it appears that the majority of courses that engage making at full-scale tend to be irregularly offered and elective in nature. As such they are often isolated from the regular, required curriculum. However, through the experiments of pioneering faculty and administrators working within existing curricular structures full-scale teaching is are impacting that way schools describe, or construct, their aspirations and structure their degree programs. As such, the examples provide an opportunity to imagine potential curricular strategies for a possible future in which the conventions surrounding interiors, at least within the academy, evolve to include material acts of construction as a matter of course.

\section{ENDNOTES}

1. Juhani Pallasmaa, "The Architecture of the Seven Senses," in Toward a New Interior: An Anthology of Interior Design Theory, ed. Lois Weinthal (New York: Princeton Architectural Press, 2011), 42.

2. Hans Jonas, "The Nobility of Sight" in Philosophy and Phenomenological Research, Vol. 14, No. 4 (1954), 507.

3. Mary Woods, From Craft to Profession: The Practice of Architecture in Nineteenth-Century America. (Berkeley, California: University of California Nineteenth-Centu
Press, 1999), 9.

4. Dana Cuff, Architecture: The Story of Practice. (Cambridge, Massachusetts: MIT Press, 1991), 45 
5. Grace Lees-Maffei, "Introduction: Professionalization as a Focus in Interior Design History," Journal of Design History, Vol. 21 No. 1 (2008), 7.

6. Jen Browne, "Decisions in DIY: Women, Home Improvements and Advertising in Post-War Britain" in All the World and Her Husband: Women in Twentie Cassell, 2000), 131-145.

7. Grace Lees-Maffei, "Introduction: Professionalization as a Focus in Interior Design History," Journal of Design History, Vol. 21 No. 1 (2008), 11.

8. William W. Braham, "A Wall of Books: The Gender of Natural Colors in Modern Architecture," Journal of Architectural Education, Vol 53, No. 1 (1999), 7.

9. Steven Cahn, Classic and Contemporary Readings in the Philosophy of Education. (New York : McGraw Hill, 1997), 274.

10. John Dewey, "Experience and Education," in Classic and Contemporary Readings in the Philosophy of Education. (New York : McGraw Hill, 1997), 327-328.

11. Paulo Friere, "Pedagogy of the Oppressed," in Classic and Contemporary Readings in the Philosophy of Education. (New York : McGraw Hill, 1997), 46

12. Adam Hopfner, "Foreword," in Design-Build Studio: Crafting Meaningful Work in Architecture Education, ed. Tolya Stonorov. (New York: Rutledge, 2018).

13. Brian Mackay-Lyons, Ghost: Building an Architectural Vision. (Princeton: Princeton Architectural Press, 2008), 135 and 138.

14. Michael Hughes, "RE-constructing Pedagogy" in Design/Education: Proceedings of the 7th International Conference of the Assoc. of Architecture Schools of Australasia, ed. D Ramirez-Lovering, J. Alexander, and A. Fairley. (Melbourne, Australia: The Association of Architecture Schools of Australasia, 2013), 9.

15. Andrea Dean, "Samuel Mockbee: A Life's Work," in Architectural Record (June 2004)

16. Geoff Gjertson, "House Divided: Challenges to Design/Build from Within," in 2011 ACSA Fall Conference Proceedings. (Washington, DC: ACSA, 2011)

17. Margaret Konkel, "Build-to-Learn: An Examination of Pedagogical Practices in Interior Design," in Journal of Interior Design Vol. 39, No. 2 (2014), 1 and 13.

18. Lois Wienthal, "Introduction," in Toward a New Interior: An Anthology of Interior Design Theory, ed. Lois Weinthal (New York: Princeton Architectura Press, 2011), 19.

19. “Lilian Wong Quote," accessed June 26, 2018. https://www.risd.edu/ academics/interior-architecture/

20. “BFA | 4-year program," accessed June 26, 2018. https://www.risd.edu/ academics/interior-architecture/undergraduate/

21. "MDesP Adaptive Reuse | 2-year+ program," accessed June 26, 2018. https:// www.risd.edu/academics/interior-architecture/graduate/

22. “Building Materials Exploration," accessed June 26, 2018. https://www.risd. edu/academics/interior-architecture/courses/

23. “Promo Video," accessed June 26, 2018. http://rsid.ryerson.ca/promo-video

24. "Who We Are," accessed June 26, 2018. http://rsid.ryerson.ca/about/ who-are-we

25. Ibid

26. "Student Work: Second Year, IRD 400," accessed June 26, 2018. http://rsid. ryerson.ca/student-work/second-year/ird-400

27. “FCAD Fab Lab," accessed June 26, 2018. http://rsid.ryerson.ca/facilities

28. Jaclyn Tersigni, "8 Top Interior Design Schools from around the World" last modified November 17, 2016. https://www.azuremagazine.com/article/ eight-top-interior-design-schools/

29. Nathan Bicak, e-mail message to author, May 11, 2018.

30. Ibid

31. "Interior Architecture Course Details," accessed June 26, 2018. https://woodbury.edu/program/school-of-architecture/programs/interior-architecture/

32. James Sullivan, e-mail message to author, October 18, 2017.

33. Geoff Gjertson, "House Divided: Challenges to Design/Build from Within," in 2011 ACSA Fall Conference Proceedings. (Washington, DC: ACSA, 2011)

34. "RISD 2nd Life- FINAL," accessed July 6, 2018. http://portfolios.risd.edu/ gallery/14920457/RISD-2nd-Life-FINAL 